\title{
Elastic and Plastic Strains and Watt Losses in Grain-Oriented 3 Pct Si-Fe
}

\author{
by Peter W. Neurath and Robert E. Waite
}

$\mathbf{I}^{\mathrm{N}}$ NFORMATION is available on the effect of stress on permeability, coercive force, and hysteresis for a variety of materials ${ }^{1}$ but for the technically important grain-oriented 3 pct $\mathrm{Si}-\mathrm{Fe}^{2}$ the stress effects are not adequately covered in the literature; in addition, most of the stress data do not permit estimation of what would happen to the 60 cycle watt losses of the material under stress. Direct measurement of these effects therefore has been made and appears to be of considerable theoretical as well as practical interest. Losses were measured on the central $25 \mathrm{~cm}$ portion of $40 \times 3 \times 0.035 \mathrm{~cm}$ samples which could be stressed in a small tensile machine built for this purpose. Under tension the following effects, illustrated in the figures by a particular example, were observed:

1-"Unstrained" material of commercially acceptable loss level shows no change or a small increase in loss at low elastic stresses. For the sample shown in the figures, this is illustrated during the initial run, where a 7 pct increase is observed (Fig. 1).

2-There is no additional change in loss when the sample is further strained up to the elastic limit (Fig. 1). Within that limit the loss-stress curve is reversible. This is not illustrated in Fig. 1.

3 -Even in the plastic range only small increases in loss are observed as long as the sample is kept

P. W. NEURATH and R. E. WAITE are associated with General Electric Co., Pittsfield, Mass.

TN 265E. Manuscript, Sept. 27, 1954. under stress (Fig. 2, point $N$ ); often no increase can be observed (Fig. 1).

4-A large increase in watt losses is observed after removal of the stress subsequent to plastic deformation (Figs. 1 and 2).

5-All, or nearly all, of the foregoing increase in loss due to plastic deformation can be eliminated by a reapplication of tensile stress but returns upon removal of this stress. This is illustrated in the third run (Fig. 3). This run remains within the elastic limit and shows the reversibility of the stress-loss curve under this condition.

These findings have been confirmed on large samples (approximately 200x10x0.035 cm and larger) except that under 1 no initial increase in loss was ever observed on these. The accuracy of the watt loss measurements is of the order of 1 pct.

Neither bending of the sample in the tensioning device nor a redistribution of flux along the width of the sample accounts for these results. They therefore must be explained on the basis of either a change in the domain configuration due to stress or a change in the domain wall mobility.

\section{Acknowledgment}

The assistance of Mr. Robert L. TenBroeck with the instrumentation is gratefully acknowledged.

\footnotetext{
${ }^{1}$ R. M. Bozorth: Ferromagnetism. (1951) Chap. 13. New York D. Van Nostrand Co.

2 R. M Bozorth: Ferromagnetism. (1951) Chap. 13, p. 88. New York. D. Van Nostrand Co.
}

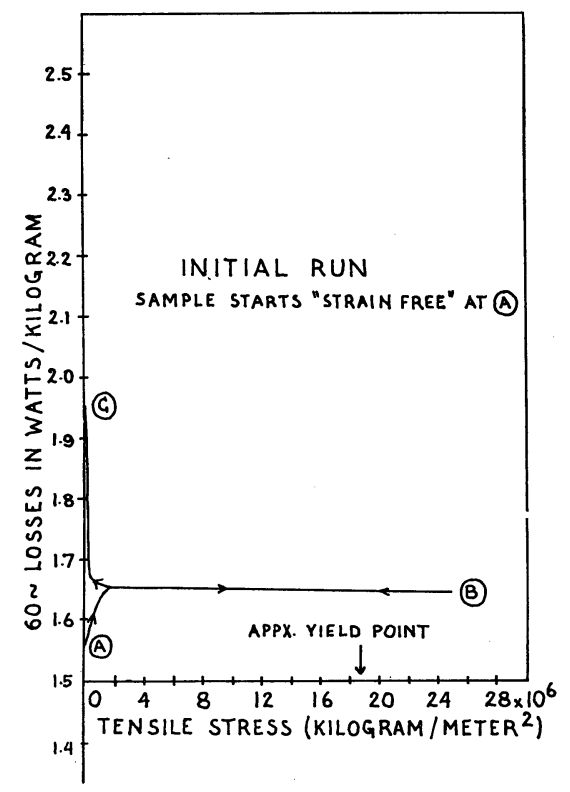

Fig. 1-Change of 60 cycle watt loss of grain-oriented 3 pct $\mathrm{Si}-\mathrm{Fe}$ under tension. Losses were measured at a peak flux density of 15,500 gauss. The initially strain free sample $(A)$ was stressed beyond the yield point $(B)$ and, after complete release of the tension, had increased in losses $(C)$.
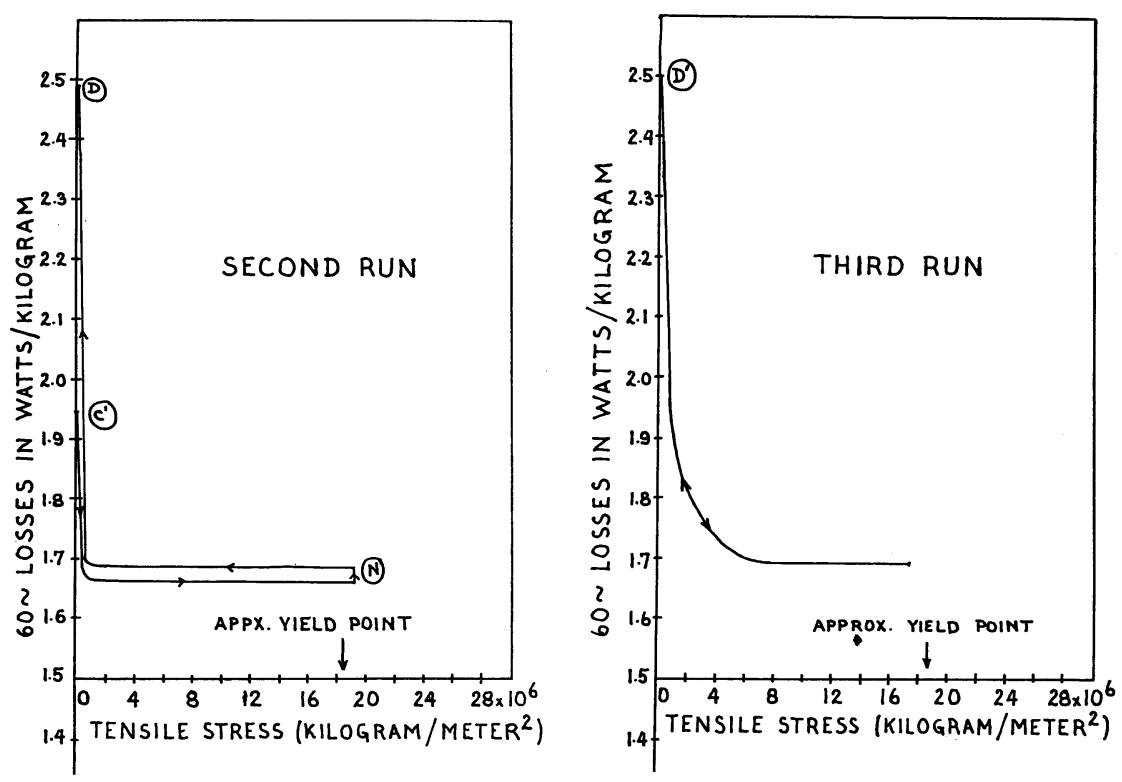

Fig. 2-A second run on the same sample as in Fig. 1. At the maximum stress $N$, Neumann bands could be heard to form. The initial point $C^{\prime}$ is identical with $C$ of Fig. 1 .
Fig. 3-A third run on the same sample as shown in Figs. 1 and 2 . This run remained within the elastic limit. Its initial point $D^{\prime}$ is identical with $D$ of Fig. 2. 